\title{
Body Pushers: Low-Dose CT, Always the Best Choice? A Study of the Diagnostic Performance of CT Scout View
}

\author{
Robin Fabian Gohmann', Frauke Heckner², Diane Uschner ${ }^{3}$, Christiane Katharina Kuhl1, \\ Sebastian Daniel Reinartz ${ }^{1}$ \\ ${ }^{1}$ Department of Diagnostic and Interventional Radiology, University Hospital, RWTH Aachen University, Aachen, Germany \\ ${ }^{2}$ University Hospital, RWTH Aachen University, Aachen, Germany \\ ${ }^{3}$ Department of Medical Statistics, University Hospital, RWTH Aachen University, Aachen, Germany \\ Email: robin.gohmann@gmx.de
}

How to cite this paper: Gohmann, R.F., Heckner, F., Uschner, D., Kuhl, C.K. and Reinartz, S.D. (2017) Body Pushers: LowDose CT, Always the Best Choice? A Study of the Diagnostic Performance of CT Scout View. Open Journal of Radiology, 7, 112120.

https://doi.org/10.4236/ojrad.2017.72013

Received: May 2, 2017

Accepted: June 17, 2017

Published: June 20, 2017

Copyright $\odot 2017$ by authors and Scientific Research Publishing Inc. This work is licensed under the Creative Commons Attribution International License (CC BY 4.0).

http://creativecommons.org/licenses/by/4.0/

\begin{abstract}
Purpose: The purpose of this study has been to evaluate the diagnostic information contained in the CT scout view in the detection of body packing. Materials and methods. Retrospect analysis of 43 CT scans between July 2011 and June 2013 in asymptomatic suspects of body packing (29 men, 14 females, mean age $38 \pm 9$ years). Results. A total of 11 positive cases of body packing were identified. In $10(91 \%)$ of the cases packets were relatively large and spares in number ( 3 or less); in 7 (64\%) a single packet has been identified. 6 $(55 \%)$ of the packets were located rectally, $4(36 \%)$ vaginally and in $1(9 \%)$ case multiple small packets of approximately $1 \mathrm{~cm}$ in size were found to have been ingested orally. Maximum and minimum diameters were $5.9 \pm 3 \mathrm{~cm}$ and $2.9 \pm 1.4 \mathrm{~cm}$, respectively. The mean weight of packets was $7.5 \pm 4.2 \mathrm{~g}$ (range 2 - $54 \mathrm{~g})$. In $73 \%(\mathrm{n}=8)$ heroin had been detected; other drugs such as cocaine $(n=1)$ and cannabis $(n=1)$ were encountered once, respectively. One packet was identified retrospectively and its content could therefore not be identified. The average effective dose was $3.8 \pm 2.1 \mathrm{mSv}$ for CT, of that $0.12 \pm$ $0.01 \mathrm{mSv}$ was required for the CT scout view. Conclusion: If CT scout view were treated as a diagnostic image, some CT scans may be omitted, thereby maintaining streamlined operations and achieving further dose reduction jointly in the workup of body packing.
\end{abstract}

\section{Keywords}

Body Packing, CT Scout View, CT, Dose Reduction, X-Ray

\section{Introduction}

Drug trafficking with intracorporal concealment of packets for transport, in this 
study referred to as body packing (BP), is known in the medical community since the 70s [1]. Today cases in all age groups, including children and pregnant women, have been reported [2] [3] [4] [5] [6]. Though many possibilities for its detection exist, ranging from X-ray [3] [4] [7]-[12] and CT [4] [7] [8] [10] [12] [13] to MRI [14], ultrasound [5] [9] and less well known methods as low-dose linear slit digital radiography "LSDR and Lodox" [8], the most established examination methods remain X-ray and CT.

Since imaging characteristics of BP vary it remains difficult to prove or exclude BP as it is not limited to a single substance (e.g. heroin, cocaine) or mode of packaging (e.g. condom, foil wrapping) [3]. A further complicating factor can be the localisation of the packets within the gastrointestinal tract and consequently accompanying superimposed structures such as gas, compacted stool or bony structures, each depending on the time and mode of application (oral, rectal, vaginal). As a consequence, imaging characteristics differ and diagnostic performance of both X-ray and CT ultimately vary, deeming a plain X-ray often insufficient.

Recently more studies have given way to the scout view as a diagnostic image in select clinical questions [15] [16]; one study demonstrated an especially high PPV in body packers with packets in the upper and mid GI [17], while an animal study could even show better delineation of foreign objects with a CT scout view compared to X-ray, while applying equivalent or lower radiation doses when compared to X-ray [12].

Even though a CT scout view differs drastically in radiation dose from a CT scan or even plain X-ray, its diagnostic performance remains to be evaluated in the clinical setting of body packing.

Though in most cases radiologists are not involved directly in the legal investigation, they determine which examination method to use and it remains their obligation to protect any individual undergoing such examinations from unnecessary risks [18] that any radiation based study may pose.

The purpose of this study, therefore, was to analyze the diagnostic performance of the CT scout view against that of the CT examination in cases of suspected BP performed at our department.

\section{Material and Methods}

The study has been conducted retrospectively and was approved by the local ethics committee in our tertiary care center.

We included at total of 43 consecutive CT examinations in cases of suspected body packing between July 2011 and June 2013. Two individuals have been detained on different occasions with the suspicion of body packing, each occasion had been consider as an independent case.

We examined 14 female (33\%) and 29 male (67\%) cases with a mean age of $38 \pm 9$ years.

Individuals with apparent signs of intoxication, bowel obstruction or perforation were managed medically or surgically and not considered in this study. 


\subsection{CT Imaging}

Non contrast enhanced CT-imaging was acquired from the dome of the diaphragm to the pubic symphysis.

Images were acquired with a 40-row Multislice-CT-scanner (SOMATOM Definition AS, Siemens Healthcare, Erlangen, Germany) with the following parameters: tube voltage, $100 \mathrm{kV}$; tube current modulation (Care Dose); fixed reference current, $60 \mathrm{mAs}$; collimation, $0.6 \times 40$; rotation time, 500 milliseconds; pitch, 1.4. For scan volume planning a standard scout view at $120 \mathrm{kV}$ with a tube current of $35 \mathrm{~mA}$ was acquired anteroposteriorly.

No IV or enteral contrast medium was used.

Images were isovolumetrically reconstructed using a filtered back projection soft tissue kernel (B20f) with a slice thickness of $1 \mathrm{~mm}$ (increment $0.7 \mathrm{~mm}$ ) and $5 \mathrm{~mm}$ (increment $4 \mathrm{~mm}$ ) in axial direction, respectively. Multislice reformations were performed sagittally and coronally.

\subsection{Image Evaluation}

Images were read on a routine digital reporting station with standard PACS viewer (iSite Radiology, Philips Healthcare, Amsterdam, Netherlands). CT images and CT scout views were evaluated independently from each in randomized order, beginning with the CT scout views.

The images were rated on the presence of foreign objects on a four point Likert scale (definite BP, likely BP, improbable BP, no BP) by three radiologists with 4,5 and 7 years of clinical experience, respectively. For the scout view bowel gas was rated on a four point Likert scale (1 no gas, 4 meteorism). If a foreign body was identified on the $\mathrm{CT}$ scan, maximum and minimum diameters were recorded in the coronal reformation.

\subsection{Standard of Reference}

The standard of reference for this study is a consensus read of the CT images with knowledge of the legal body's investigation results, in which the authorities have consistently recorded the type and weight of active illegal substance.

\subsection{Statistics}

"R" [19] was used for the statistical analysis. The diagnostic performance of CT scout view on the basis of the median rating of three observers was compared to that of CT scan. We compared both sensitivity and specificity of CT scans and CT scout views. Values of definite and likely BP were summarized as positive result; values of improbable and definitely no $\mathrm{BP}$ were summarized as negative result. Furthermore, we evaluated the agreement of each CT scan and its corresponding CT scout view with the Cohen's kappa coefficient. The agreement of the three observers with respect to CT scan and CT scout view was evaluated with Cohen's kappa coefficient separately. In addition, we evaluated the influence of packet size and bowel gas on the detection rate of CT scout view. 


\section{Results}

A total of 11 positive cases of body packing were identified. In 10 (91\%) of the cases packets were relatively large and spares in number (3 or less), in 7 (64\%) a single packet has been identified. 6 (55\%) of the packets were located rectally, 4 (36\%) vaginally and in 1 (9\%) case multiple small packets of approximately $1 \mathrm{~cm}$ in size were found to have been ingested orally. Maximum and minimum diameters were $5.9 \pm 3 \mathrm{~cm}$ and $2.9 \pm 1.4 \mathrm{~cm}$, respectively. The mean weight of packets was $7.5 \pm 4.2 \mathrm{~g}$ (range $2-54 \mathrm{~g})$. In $73 \%(\mathrm{n}=8)$ of cases heroin had been detected, other drugs such as cocaine $(n=1)$ and cannabis $(n=1)$ were encountered once, respectively. One packet was identified retrospectively and its content could therefore not be identified. The average effective dose was $3.8 \pm 2.1$ $\mathrm{mSv}$ for CT, of that $0.12 \pm 0.01 \mathrm{mSv}$ was required for the CT scout view.

\section{Interpretation of Results}

The prevalence of body packing was $26 \%$ (11/43). CT scout view had a sensitivity of $72 \%(8 / 11)$ and a specificity of $84 \%(27 / 32)$. CT scan had a sensitivity of $100 \%$ and a specificity of $97 \%(31 / 32)$. CT scout view failed to detect 3 cases of true body packing, and falsely detected 5 cases of body packing. CT scan never failed to detect true body packing and detected body packing falsely only once.

Cohen's kappa coefficient for the comparison of CT scout view and CT scan on patient level showed a substantial agreement (Cohen's kappa of 0.61) between the two methods, indicating that CT scout view is a good index for CT scan.

For CT scout view the size of the packet (maximal diameter) may have an influence on the detection rate of body packing. The model including the size, fitted the data better than the model without that parameter (model comparison with analysis of variance yielded a $\mathrm{p}=0.01076$ ). However, size was not statistically significant in the logistic regression with the relatively small number of positive cases. As sensitivity was $100 \%$ for CT scan, the size of the packet did not have an influence on the detection rate.

If readers were viewed individually, and only considered the cases read positively with high confidence, PPV increased to $92 \%$ with a correspondingly high likelihood ratio. However, considering the relatively low number of positive cases $(n=11)$, statistical significance was not reached. No significant change for NPV could be observed, as a negative read with high confidence was only given 4 times in total.

\section{Discussion}

$\mathrm{X}$-ray and CT are the modalities of choice in clinical practice in the evaluation of BP today as they are both readily available and rapid, and only require limited cooperation of the individual [3] [4] [7]-[13] [20] [21] [22]. Often enough an $\mathrm{X}$-ray is read as equivocal in the evaluation of BP, whereas other times a diagnosis of BP can be can be made with confidence.

This study's goal was to evaluate the diagnostic information contained in the CT scout view in suspects of BP. 
The sensitivity of a typical X-ray in diagnosing BP has been reported to ranging from $47 \%$ - 95\% [21] [23], the sensitivity of CT has been reported to be close to $100 \%$ [3] [24]. The sensitivity of CT scout view in our human collective of mostly body stuffers was $73 \%$ with an especially high PPV, consistent with the higher sensitivity of CT scout view when compared to X-ray as reported in an animal model [12] or for body packing with packets in the upper and mid GI [17].

Nevertheless, in many cases it remains difficult to prove or exclude body packing even with the many times good of foreign objects achieved with the CT scout view, as body packing is not limited to a single substance (heroin, cocaine e.g.) or mode of packaging (condom, foil wrapping e.g.) [3] or other complication factors as the localization of the packets within the gastrointestinal tract and consequently accompanying superimposed structures such as gas, compacted stool or bony structures, each depending on the time and mode of application (oral, rectal, vaginal); especially hardened stool in the rectum with surrounding gas was many times difficult to differentiate from a packet. As a consequence of differing imaging characteristics, CT scout view is exposed to the same challenges any projection radiography.

However, if a diagnosis of BP can be made with high confidence, an example of which is shown in Figure 1 and Figure 2, the examination can be concluded. In other cases as e.g. depicted in Figure 3 one can proceed to the CT scan without further delay, streamlining the workup of BP.

An additional benefit of the CT scout view is its extremely low dose (reduction of roughly 40 fold compared to the CT scan and up to 5 fold when compared to X-ray [17] [25]) and when followed up by the actual CT scan, being essentially dose neutral.

There were several limitations to our study. Drug packets found were mostly very spare or solitary in number, therefore many frequently encountered X-ray

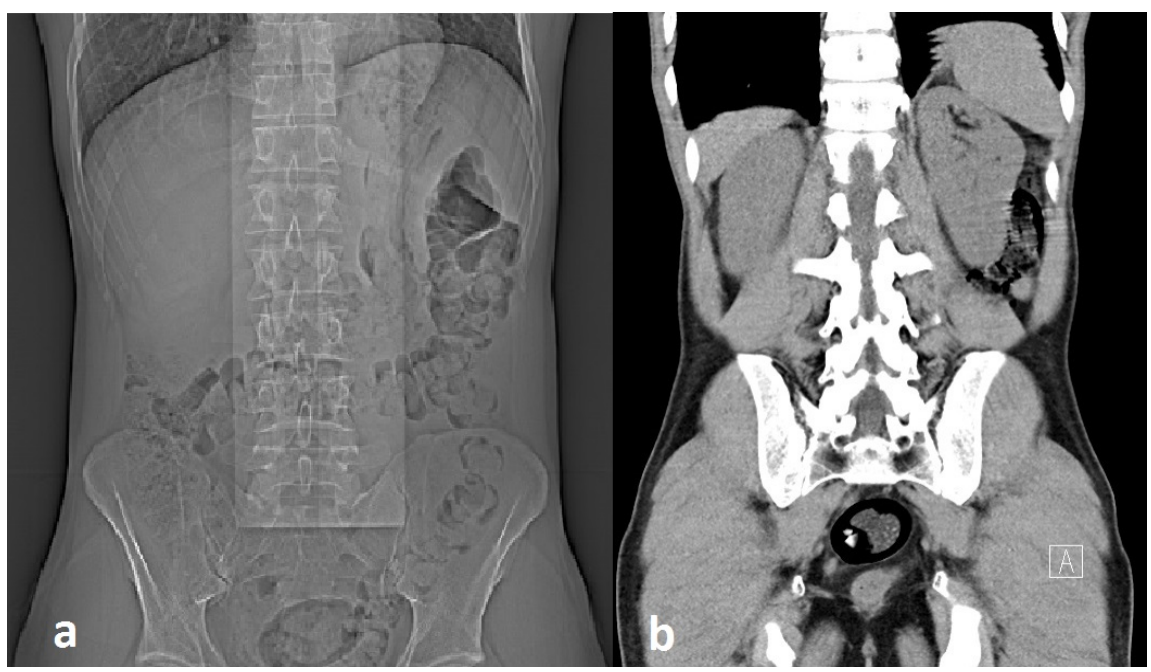

Figure 1. (a) CT scout view of a body packing suspect with a single large well visible packet in projection of the rectum. (b) Low-dose CT in coronal plane of the same individual. 


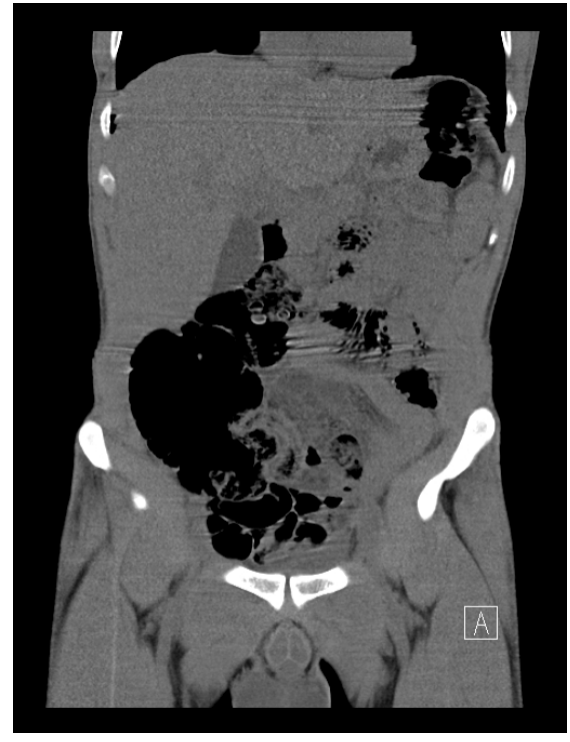

Figure 2. CT scout view of a body packing suspect clearly showing multiple smaller foreign bodies in the rectum.

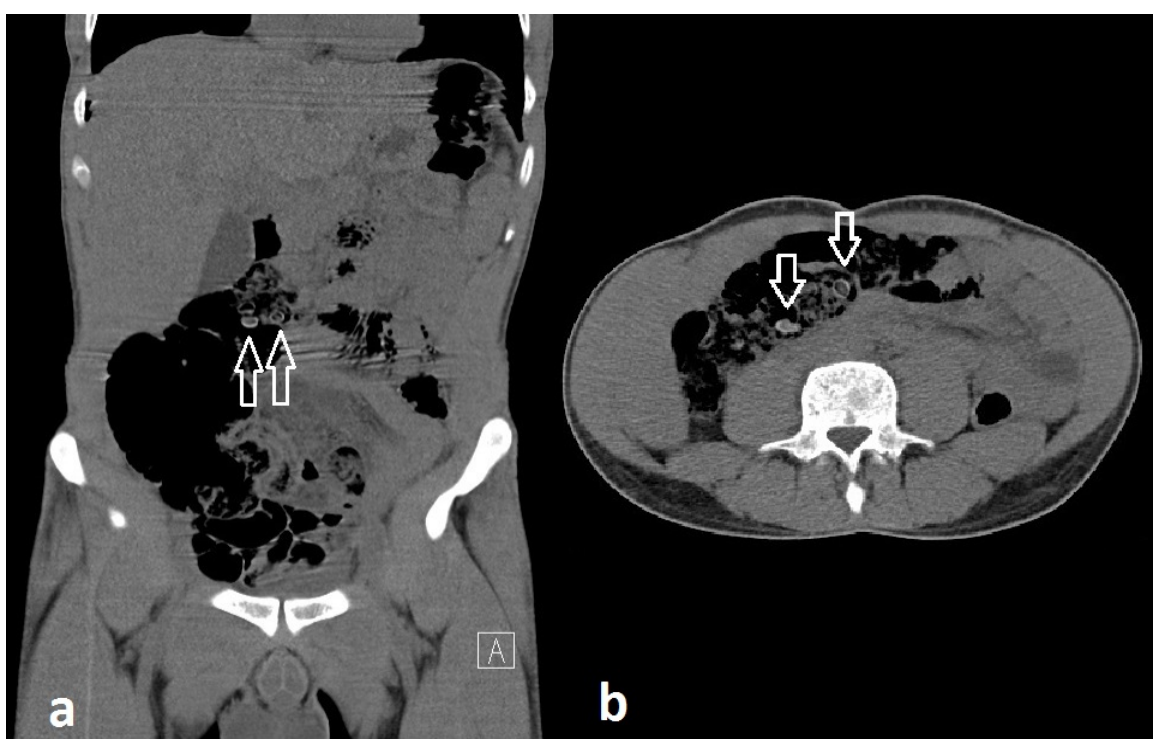

Figure 3. Low-dose CT of a body packing suspect with multiple round objects in the transverse colon with a diameter of approximately $1 \mathrm{~cm}$ in (a) coronal and (b) axial plain. Notice the X-ray density is very similar to the surrounding stool. The CT scout view in this case was not suspicious.

signs such as parallelism or "tic-tac" sign [4] were not present. As this is owed to local habits generalization to other regions may be difficult. Similarly, heroin in powder form combined with cutting agents was by far the most frequently encountered drug; liquid packets as increasingly reported in other studies were not found, possibly complicating generalization further.

Packet characteristics, such as number of packets, packaging, total weight, or composition were not consistently recorded and could therefore not be evaluated, e.g. only in three cases the packaging material was recorded by the authori- 
ties.

Finally, the standard of reference is intrinsically flawed, being limited by diagnostic and legal limitations: The legal body's investigation and the consensus reading of images could not in every positive case be verified; either the foreign object was overlooked when initially reported, which then let to the release of the suspect or, although a foreign object was reported, which also was clearly visible on the consensus read and the suspect was placed in confinement, in some cases no such object could be retrieved.

\section{Conclusions}

CT scout view demonstrated good delineation of packets in body pushers with an especially good PPV and slightly higher sensitivity and specificity, when compared to X-ray. Though slightly less severe, its limitations in the detection of body packing, namely the relatively low specificity and sensitivity, are identical to X-ray. Despite these major limitations, the information contained within the CT scout view should be utilized and advancement to CT scan should be reserved for equivocal or negative cases, when suspicion remains high.

If $\mathrm{CT}$ scout view were treated as a diagnostic image, some CT scans may be omitted, thereby maintaining streamlined operations and achieving further dose reduction jointly in the workup of body packing.

\section{References}

[1] Deitel, M. and Syed, A.K. (1973) Intestinal Obstruction by an Unusual Foreign Body. Canadian Medical Association Journal, 109, 211-212.

[2] Beno, S., Calello, D., Baluffi, A. and Henretig, F.M. (2005) Pediatric Body Packing: Drug Smuggling Reaches a New Low. Pediatric Emergency Care, 21, 744-746. https://doi.org/10.1097/01.pec.0000186428.07636.18

[3] Hergan, K., Kofler, K. and Oser, W. (2004) Drug Smuggling by Body Packing: What Radiologists Should Know about It. European Radiology, 14, 736-742. https://doi.org/10.1007/s00330-003-2091-5

[4] Poletti, P.A., Canel, L., Becker, C.D., et al. (2012) Screening of Illegal Intracorporeal Containers (“Body Packing”): Is Abdominal Radiography Sufficiently Accurate? A Comparative Study with Low-Dose CT. Radiology, 265, 772-779. https://doi.org/10.1148/radiol.12112767

[5] Shahnazi, M., Sanei Taheri, M. and Pourghorban, R. (2011) Body Packing and Its Radiologic Manifestations: A Review Article. Iranian Journal of Radiology, 8, 205210. https://doi.org/10.5812/iranjradiol.4757

[6] Traub, S.J., Kohn, G.L., Hoffman, R.S. and Nelson, L.S. (2003) Pediatric "Body Packing”. Archives of Pediatrics \& Adolescent Medicine, 157, 174-177. https://doi.org/10.1001/archpedi.157.2.174

[7] Bulakci, M., Kalelioglu, T., Bulakci, B.B. and Kiris, A. (2013) Comparison of Diagnostic Value of Multidetector Computed Tomography and X-Ray in the Detection of Body Packing. European Journal of Radiology, 82, 1248-1254. https://doi.org/10.1016/j.ejrad.2012.12.022

[8] Flach, P.M., Ross, S.G., Ampanozi, G., et al. (2012) Drug Mules as a Radiological Challenge: Sensitivity and Specificity in Identifying Internal Cocaine in Body Pack- 
ers, Body Pushers and Body Stuffers by Computed Tomography, Plain Radiography and Lodox. European Journal of Radiology, 81, 2518-2526. https://doi.org/10.1016/j.ejrad.2011.11.025

[9] Hierholzer, J., Cordes, M., Tantow, H., et al. (1995) Drug Smuggling by Ingested Cocaine-Filled Packages: Conventional X-Ray and Ultrasound. Abdominal Imaging, 20, 333-338. https://doi.org/10.1007/BF00203366

[10] Schulz, B., Grossbach, A., Gruber-Rouh, T., et al. (2014) Body Packers on Your Examination Table: How Helpful Are Plain X-Ray Images? A Definitive Low-Dose CT Protocol as a Diagnosis Tool for Body Packers. Clinical Radiology, 69, e525e530. https://doi.org/10.1016/j.crad.2014.08.019

[11] Sormaala, M.J., Salonen, H.M., Mattila, V.M., Kivisaari, A. and Autti, T. (2012) Feasibility of Abdominal Plain Film Images in Evaluation Suspected Drug Smuggler. European Journal of Radiology, 81, 2118-2121.

[12] Ziegeler, E., Grimm, J.M., Wirth, S., et al. (2012) Computed Tomography Scout Views vs. Conventional Radiography in Body-Packers-Delineation of Body-Packs and Radiation Dose in a Porcine Model. European Journal of Radiology, 81, 38833889.

[13] Pache, G., Einhaus, D., Bulla, S., et al. (2012) Low-Dose Computed Tomography for the Detection of Cocaine Body Packs: Clinical Evaluation and Legal Issues. Fortschritte auf dem Gebiete der Rontgenstrahlen und der Nuklearmedizin, 184, 122-129. https://doi.org/10.1055/s-0031-1281781

[14] Bulakci, M., Ozbakir, B. and Kiris, A. (2013) Detection of Body Packing by Magnetic Resonance Imaging: A New Diagnostic Tool? Abdominal Imaging, 38, 436-441. https://doi.org/10.1007/s00261-012-9972-5

[15] Brook, O.R., Guralnik, L. and Engel, A. (2007) CT Scout View as an Essential Part of CT Reading. Australasian Radiology, 51, 211-217. https://doi.org/10.1111/j.1440-1673.2007.01715.x

[16] Ege, G., Akman, H., Kuzucu, K. and Yildiz, S. (2004) Can Computed Tomography Scout Radiography Replace Plain Film in the Evaluation of Patients with Acute Urinary Tract Colic? Actaradiologica, 45, 469-473. https://doi.org/10.1080/02841850410005264

[17] Aissa, J., Kohlmeier, A., Rubbert, C., et al. (2016) Diagnostic Value of CT-Localizer and Axial Low-Dose Computed Tomography for the Detection of Drug Body Packing. Journal of Forensic and Legal Medicine, 37, 55-60.

[18] Smith-Bindman, R., Lipson, J., Marcus, R., et al. (2009) Radiation Dose Associated with Common Computed Tomography Examinations and the Associated Lifetime Attributable Risk of Cancer. Archives of Internal Medicine, 169, 2078-2086. https://doi.org/10.1001/archinternmed.2009.427

[19] R: Development Core Team (2011) R: A Language and Environment for Statistical Computing. http://www.R-project.org

[20] Bogusz, M.J., Althoff, H., Erkens, M., Maier, R.D. and Hofmann, R. (1995) Internally Concealed Cocaine: Analytical and Diagnostic Aspects. Journal of Forensic Sciences, 40, 811-815. https://doi.org/10.1520/JFS15390J

[21] Booker, R.J., Smith, J.E. and Rodger, M.P. (2009) Packers, Pushers and Stuffers-Managing Patients with Concealed Drugs in UK Emergency Departments: A Clinical and Medicolegal Review. Emergency Medicine Journal, 26, 316-320. https://doi.org/10.1136/emj.2008.057695

[22] Maurer, M.H., Niehues, S.M., Schnapauff, D., et al. (2011) Low-Dose Computed Tomography to Detect Body-Packing in an Animal Model. European Journal of 
Radiology, 78, 302-306.

[23] Traub, S.J., Hoffman, R.S. and Nelson, L.S. (2003) Body Packing-The Internal Concealment of Illicit Drugs. The New England Journal of Medicine, 349, 25192526. https://doi.org/10.1056/NEJMra022719

[24] Yang, R.M., Li, L., Feng, J., et al. (2009) Heroin Body Packing: Clearly Discerning Drug Packets Using CT. Southern Medical Journal, 102, 470-475. https://doi.org/10.1097/SMJ.0b013e31819ecacc

[25] Nauer, C.B., Kellner-Weldon, F., Von Allmen, G., Schaller, D. and Gralla, J. (2009) Effective Doses from Scan Projection Radiographs of the Head: Impact of Different Scanning Practices and Comparison with Conventional Radiography. AJNR American Journal of Neuroradiology, 30, 155-159. https://doi.org/10.3174/ajnr.A1293

Submit or recommend next manuscript to SCIRP and we will provide best service for you:

Accepting pre-submission inquiries through Email, Facebook, LinkedIn, Twitter, etc. A wide selection of journals (inclusive of 9 subjects, more than 200 journals)

Providing 24-hour high-quality service

User-friendly online submission system

Fair and swift peer-review system

Efficient typesetting and proofreading procedure

Display of the result of downloads and visits, as well as the number of cited articles Maximum dissemination of your research work

Submit your manuscript at: http://papersubmission.scirp.org/

Or contact ojrad@scirp.org 